\title{
Shifting to open education in our digital learning
}

\author{
Royce Kimmons ${ }^{1}$
}

Published online: 9 February 2021

(c) Association for Educational Communications and Technology 2021

\begin{abstract}
In this special issue, we have gathered seven scholarly responses to Hilton's 2016 article, representing leading edge perspectives on OER in terms of research, theory, and practice to help the field to better understand how to design, use, and research OER moving forward.
\end{abstract}

\section{Shifting to open education in our digital learning}

In recent years, a variety of "open" topics have seen increased interest in the educational technology community, including open education, open educational resources (OER), open textbooks, open access, open scholarship, open pedagogies, open courseware, OERenabled pedagogies, and others. People are drawn to these topics for many reasons, but part of the appeal is that they can speak to our deep desires to use our educational technology work to engage in "ethical pursuit[s] for democratization, fundamental human rights, equality, and justice" (Veletsianos and Kimmons 2012). By being deeply democratic (OECD 2007; Siemens 2003) and allowing us to "give without giving away" (Wiley 2010), modern technologies used in open ways can offer possibilities to make learning more accessible for everyone, fundamentally reshaping and overcoming persistent barriers to learning that have created and sustained inequities for all of human history. Yet, even though most higher education faculty in my country (the U.S.) believe that open educational resources (OER) are a good idea, only $14 \%$ actually use them in any way, and only $8 \%$ of those aware of focused initiatives at their institutions will commit to using OER in the next three years (Spilovoy et al. 2020).

Why are shifts to open so minimal (or at least slow)? Rogers' (2003) diffusion of innovations model would suggest that lack of relative advantage is the primary reason for slow or limited adoption, and so it would seem to follow that for OER to see increased adoption and fulfill their potential of improving educational opportunities, their relative advantage must be firmly established in the literature and made clear to faculty and administrators.

Hilton's review articles summarizing research results on student efficacy and user perceptions associated with OER $(2016,2020)$ have been instrumental in moving the field forward in this regard, and his 2016 ETR\&D article "Open educational resources

Royce Kimmons

roycekimmons@byu.edu

http://roycekimmons.com

1 Instructional Psychology \& Technology, Brigham Young University, Provo, UT 84602, USA 
and college textbook choices: A review of research on efficacy and perceptions" remains one of the most highly-cited articles in the journal over the past four years. In both of these articles, Hilton brings together research studies from various unique contexts to clearly make the case that OER provide relative advantages to students and educational institutions by being equally efficacious to, and yet less-expensive than, their commercial counterparts. He concludes that this should lead educators "to more carefully examine the rationale for requiring students to purchase commercial textbooks when highquality, free and openly-licensed textbooks are available" (2016), pp. 588-589.

In this special issue, we have gathered seven scholarly responses to Hilton's 2016 article, representing leading edge perspectives on OER in terms of research, theory, and practice to help the field to better understand how to design, use, and research OER moving forward. The following brief synopsis of each response reveals both the diversity of reactions as well as common themes:

- Lee and Lee provide an international interpretation of the article, identifying limitations to how relative advantages of OER may be generalizable and providing encouragement and guidance for how their adoption might progress outside the U.S. context.

- Tang explains how current OER work and research needs to move beyond mere cost savings to better address pedagogical and social problems in four key ways.

- Ma articulates important areas for future research to better understand the effects of OER and what is needed to increase their adoption.

- Hodges identifies several practical ways that university faculty and leaders can move forward with such promising research evidence but also suggests that barriers to OER may be complex, requiring advocacy, training, and guidance.

- Kilickaya and Kic-Drgas argue that design and context matter both in creating and implementing OER with different students and in different contexts for affordances to be fully realized, requiring significant effort and emphasis on quality and pedagogy.

- Veletsianos discusses OER as an increasingly important means for combatting socioeconomic, racial, and gender-based inequities but also argues that they are a "mixed blessing" in terms of equity, because without purposefulness in their use toward equity and justice, they "could not only reflect inequities but reinforce them as well."

- Wiley identifies limitations of how OER studies have been historically conceptualized as a theoretical constructs and encourages us to thoughtfully look ahead in how we conceptualize such work in the future, arguing that future work "must be grounded in a theoretical framework that provides a clear rationale for why a reasonable person would expect OER use to impact student learning."

Taken together, these responses provide guidance on how we can begin to address problems of poor diffusion of OER by giving at least two clear takeaways. First, relative advantage of OER alone will not lead to their rapid adoption and the achievement of their proposed benefits of democratization, equity, and educational improvement, especially if relative advantage is merely conceptualized as cost savings (as compared to more "expansive openness" Kimmons [2016]). And second, OER design, use, and research should be intentional and thoughtful with clear theoretical grounding that focuses on quality, pedagogy, differentiation, and equity to ensure that educational futures provided through OER align with the ethics of openness and actually have the best positive impact on the world. Moving ahead in this massive collective shift to online, OER can provide drastic benefits to learners and educators alike, but without sufficient thoughtfulness in how and why we 
move toward open solutions, OER will never achieve their full potential in making learning opportunities better, more accessible, and more equitable for all.

\section{References}

Hilton, J., III. (2016). Open educational resources and college textbook choices: A review of research on efficacy and perceptions. Educational Technology Research \& Development, 64(4), 573-590.

Hilton, J., III. (2020). Open educational resources, student efficacy, and user perceptions: A synthesis of research published between 2015 and 2018. Educational Technology Research \& Development, 64(4), 573-590.

Kimmons, R. (2016). Expansive openness in teacher practice. Teachers College Record, 118(9), 9.

OECD (2007). Giving knowledge for free: The emergence of open educational resources. Retrieved from http://www.oecd.org/edu/ceri/38654317.pdf

Rogers, E. (2003). Diffusion of innovations (5th ed.). New York, NY: The Free Press.

Siemens, G. (2003). Why we should share learning resources. Retrieved from www.elearnspace.org/Artic les/why_we_should_share.htm

Spilovoy, T., Seaman, J., \& Ralph, N. (2020). The impact of OER initiatives on faculty selection of classroom materials. Bay View Analytics. Retrieved from https://www.onlinelearningsurvey.com/reports/ impactofoerinitiatives.pdf

Veletsianos, G., \& Kimmons, R. (2012). Assumptions and challenges of open scholarship. The International Review of Research in Open and Distributed Learning, 13(4), 166-189.

Wiley, D. (2010). My TEDxNYED talk. Iterating toward openness. Retrieved from https://opencontent.org/ blog/archives/1270

Publisher's Note Springer Nature remains neutral with regard to jurisdictional claims in published maps and institutional affiliations.

Royce Kimmons is an Assistant Professor of Instructional Psychology and Technology at Brigham Young University where he studies open education, social media, data mining, and technology integration. More information about his work may be found at http://roycekimmons.com. 